\title{
NEW SOCIAL ACTORS IN THE CONTEXT OF A DEVELOPING COUNTRY: COMPUTERISATION IN BRAZIL
}

\author{
Tom Dwyer \\ Universidade Estadual de Campinas (UNICAMP) \\ Sao Paulo, Brazil
}

\begin{abstract}
Against a background of sociological theories of post-industrial society, development and youth, the relationship between Brazilian adolescents and modern technologies with special reference to computers was analysed in an ethnographic study, carried out within a phenomenological perspective.
\end{abstract}

Three distinct user sub-groups were identified: secretaries, engineers and authors.

When people use computers to reorganise and make presentable what they normally work upon, they are called secretaries. As a group these users exhibit a certain fear for their own place and for their country's place in a technology-bound future. Computers are a means by which they reproduce order.

Engineers, on the other hand, take their perception of a problem and a series of skills, anchored in utilitarian values and use computers to build products designed to resolve the identified problem. They seek to link both innovation and the reproduction of order. Their computer-related skills support their perception that their own futures are guaranteed. In general they exhibit little concern about the future of their fellow citizens.

Authors seek to explore the capacities of computers and other modern technologies to develop new products. In so doing, learning, human, artistic or self development are the seeds of their creative process. They seek both to innovate and to produce change. Whilst they have a certain fear about the nation's future they express optimism about their own individual futures.

The consequences of the existence of these diverse social actors within the context of a developing economy are then examined.

\section{VISIONS OF COMPUTING AND SOCIETY}

The democratic control of society has been rendered difficult in the vast majority of underdeveloped economies not only because of the lack of appropriate institutions and traditions but also because of the lack of even weak social ties and relations of interdependence and exchange between various groups and layers in the society. Some have speculated that the rise of information technologies can help overcome such obstacles because they introduce the possibility of all citizens becoming linked to each other at very low cost, and thereby the barriers of social differences and distances can be 
reduced. In this way technology opens up the path for the construction of international human solidarities which will help democracy and development (Toffler 1980). Such an idea is high on propaganda value and low on realism; rather, the path towards development and democracy is far more complex than that supposed by technological utopians.

A current fear, common in under-developed countries, is that information technology will do the exact reverse of that which the utopians imagine. These technologies will be applied in such a way as to deepen existing rifts within society, producing further economic, social and political deprivations and thereby further weakening existing social ties among the excluded majorities, and through this contributing to the undermining of democracy. ${ }^{1}$

Views which attribute to technical innovations a capacity to shape the world, frequently viewed in either utopian or catastrophic terms, unfortunately pay little attention to those sociological theories of technical change and of democracy which seek to understand how such technologies are appropriated and used, and how these are associated with the emergence of 'new social actors'. In a recent article in 'Futuribles', Michel Elie (1996), after having concluded that the Internet will contribute to increase inequalities, asks if the 'world-wide technological apartheid' could not be avoided through an "energetic and consistent political intervention?"2

This opens up the question as to how a political intervention might be structured. The first area of investigation will be that of development theory, the second, that of the question of creativity (which is seen as so important in post-industrial society) and the third involves a short incursion into the sociology of youth. This short study points to the importance of analysing the relationship between youth and computing technologies so as to build insights capable of making a contribution to a sociology of post-industrial development and in this way open up new areas for policy development and the enhancement of human choice.

\section{DEVELOPMENT THEORY}

To build a theoretical reflection as to the bases of economic development in a post-industrial society it is worthwhile reflecting for a few moments on the rise of industrial society. The passage from pre-industrial to industrial society was associated with the emergence of new social actors: an industrial bourgeoisie, engineers, accountants, professionals in general, bureaucrats of the modern state, trade unionists, workers movements and their political parties, to give examples. These actors worked, with varying influence, on the course of development of each industrialising society, so as to shape its social structure, economic development and capacities for political and social action of citizens. In this manner social actors, building on their traditions or breaking with the same, were able to construct societies that today appear quite different from one another in political (e.g. democratic or authoritarian, centralised or decentralised), economic (e.g. 
developed or underdeveloped, with consumers holding materialistic or nonmaterialistic values) and social (e.g. relatively egalitarian or not) terms.

The history of the relative strength of the different social forces and of the outcomes is, when read from viewpoints which recognise the capacities of societies to endogenously produce their own history, one of the history of social actors and their interrelationships and of the stability and change of these. Such a historically backgrounded perspective leads me to accord priority to the search for emergent social actors in order to understand the emergent information society. Once located it is necessary to construct theories capable of generating hypotheses as to how to strengthen the action of those who seek to achieve specified economic (e.g. development), political (e.g. democracy) and social (e.g. decreasing inequalities) goals.

Today we are able to see that the rising post-industrial society (to use Alain Touraine's theory which was developed before the emergence of computerisation as a widespread process for the treatment of information (Touraine 1969)) which perceived the centrality of knowledge in the building of a new social, economic, political and cultural order and its struggles. Indeed, the last two decades have been accompanied by the rise of many struggles around social issues such as feminism, ecology and regionalism previously not subject to this kind of attention. Together with the emergence of new social actors and groups these struggles have contributed to reshape ideas and priorities in relation to the future of economically developed nations. In these same nations it is important to note that a large part of the classic problems of industrialising societies has been attenuated.

In their efforts to industrialise many developing countries did not produce new autonomous social actors, with values, access to investment capital, political capacities and qualifications appropriate to the development of a vigorous, private sector based, capitalist economy. In many parts of the world authoritarian regimes attempted to develop the economy: the State was attributed a central role as organiser of the insertion of economic agents into the economy and of building the bodies that would guarantee their interlinkages. In many places the State also ran capitalist enterprises (Cardoso e Faletto 1973). Such a development process frequently required large investments by multi-national capital and was associated with the growth of local elites, this occurred especially in those sectors such as construction and telecommunications which were subjected to protective umbrellas.

In Brazil, industrial development attempts produced a classic case of a dual society. Those linked, whether as owners or workers, to the industrial and financial sectors became increasingly wealthy and distant from those whose lives were still dominated by capital and qualification starved industrialising processes and by pre-industrial shackles. 
In more recent years the loss of power by authoritarian governments in nearly all of Latin America has made the emergence of local elites who act with greater autonomy than in the past: they act so as to favour different relationships between industrialisation and foreign investments. One consequence of this has been a series of demands for the withdrawal of the State from many areas of commercial, economic and industrial activity.

The emergence of a post-industrial society which places information at the centre of production and consumption activities burrows underneath the ground upon which industrial societies had been built up! In this new context industrially based elites frequently lose faith in the capacity of their values, investment choices, political structures, organisation and qualifications to produce sustained development. This is reflected everywhere in bankruptcies and mergers.

To promote a cycle of growth in a post industrial age which avoids the development of 'technological apartheid' requires the emergence of social actors capable of producing alternative cultural and political fields and forms of social organisation and economic activity.

From the perspective of development theory, a series of key questions can be formulated. How can these social actors be located before they become generally visible? How can their growth be stimulated? Can the social scientist identify ways to guarantee the promotion of values which favour economic, political and social development in harmony with humanitarian, democratic and human development ideals?

The presuppositions that underlie the above interrogations can, of course, be questioned. One key question is, what does development mean? The past certainty about what exactly development is has been lost, however there is general agreement as to what underdevelopment is. It is defined through a series of accepted indicators which include illiteracy, high rates of infant mortality and hunger. However, these and other difficulties of definition do not reduce the importance of identifying the emergent new social actors in the context of the development of a post-industrial society and the nature of their perceptions of the world.

Daniel Bell has identified the capacity for innovation as one of the key forces operating in a post-industrial society. I shall now turn to a short investigation of its role.

\section{CREATIVITY}

For Daniel Bell, "the capacity for innovation doesn't adjust itself to the classical categories of power or influence and it constitutes a real force in the society" (Bell 1973). 
In information societies creativity is coming to be seen as a key force of production. Stanford economist Paul Romer has theorised that the basis for building a healthy economy in the post industrial era is to be found in the capacity to produce creatively rather than materially. Indeed, the basic economic principles which underlie his theoretical approach are quite different to those of neo-classical economics: for example, scarcity is no longer a key feature in the structuring of economic markets. Different to industrial activities which produce finite material products and where the marginal cost of each additional unit of production is typically important, informational activities produce results of which the marginal costs of reproduction are typically very low.

The hypothesis of Romer leads to the conclusion that in order to unleash creativity it is necessary to destroy or at least substitute any pre-existing culture of conformity. The rise of disciplined creativity as a force in a society will permit the development of new areas of economic, political and socio-cultural activity. But who are the carriers of the new, of the creativity that may be capable of exercising such force?

\section{YOUTH}

From groups of hackers (Levy 1984) or cyberpunks (Hafner and Markoff 1991) to individuals like Steve Jobs or Bill Gates, young people engage in a variety of projects when they involve themselves with computers. The varieties of forms of action observed teach us the importance of studying the patterns of use of computers by young (usually male) people as they construct their identities, projects, values and their future. Such patterns may indeed be carriers of the future.

However, when we move in the direction of the sociology of youth we find that very little attention is paid to the theme of youth and computing. In France, for example, where this sociology is quite vigorous, an important current has demonstrated "the cultural obstacles that are opposed to (social) mobility and to the processes of interiorisation of the objective possibilities of mobility among the young...." This type of sociology does not help in discovering the birth of new social actors among youth, however the variant propounded by Edgar Morin does. It "takes seriously the emergence (of an adolescent culture) which participates in a general process of modernisation and the evolution towards a society in which cultural and school-based affiliations become more important than class or neighbourhood affiliations, participation in a cosmopolitan culture characterises adolescents and transforms traditional identities." (Dubet 1987)

Indeed these two faces of the sociology of youth identify on the one hand those whose action reproduces social order, and on the other those who produce a new social order. Any study of youth and computers should be able to locate both kinds of social actor. Those who produce the new 
constitute, indeed, the group of major interest within the arguments so far advanced with respect to post-industrial development and creativity.

\section{USES OF COMPUTER TECHNOLOGY IN BRAZIL}

This rest of this paper relates the result of empirical research which follows closely upon an earlier article (Dwyer 1989) in which a number of hypotheses backgrounded in the earlier discussion were raised, and the framework of Touraine's post-industrial society theory was used. A key hypothesis raised was that the development of information society in developing economies would be accompanied by social progress only if were it to permit the emergence of new creative social actors capable of constructing appropriate new images of the future of society, and thereby leading to the production of economic, cultural and political elites capable of proposing and implementing these.

However, such a spirit cannot spread by itself. Manuel Castells in 'The Rise of Network Society' has isolated a series of facilitating factors including: the development of business networks, technological tools, global competition and the State (Castells 1996). The implantation of appropriate infrastructure is currently very costly in the context of a developing economy. In addition, information technology tools are generally designed in the developed world, where the parameters for their use are frequently quite different from those that would be found were the needs of people in developing nations considered.

In Brazil by the beginning of the 1990s, some important barriers to the building up of an infrastructure, that was constructed during years of a closed economy based on import substituting industrialisation, started to fall. This propitiated the rise of new social forces and a wave of investment and development. In general technologies came to be used in specific privileged environments in ways not dissimilar to the developed world, however, some innovative exceptions pointed in new directions. Electronic voting was introduced to permit reduction of fraud within the electoral system. From 1996 the Brazilian federal government greatly increased transparency by placing information about various aspects of its activities on the Internet (in the past much information was often extremely difficult to obtain, as a result of military type secrecy, chronic internal disorganisation of many formal organisations, and an 'underdeveloped' library system). In 1997 a half a million tax declarations were made via Internet and in 1998 the number was multiplied by nine! Home banking evidenced in Bill Gates' question as a 'garoto propaganda' (literally translated a 'propaganda kid') in an advertisement for the local Unibanco: "Why didn't my bank think of that?" - is a service with advanced standards. Such changes in the economic and political arenas find their place in the rapidly developing information sector of the economy and build new product and labour markets and demand new skills. However, with the exception of controls introduced against fraud within the electoral system, 
these did not appear capable of having any discernible effects on political or social life. In other words, they appear to have been associated with the reproduction of the old order far more than with the production of a new one. This observation resonates with some made in the United States where computer technology appears to have been predominantly used to rearrange pre-existing structures, rather than reorganising tasks at the same time as they computerise. Indeed the all to frequent talk about the 'productivity paradox' where the introduction of computing into complex organisations is not followed by rises in productivity is commonly believed to reflect such a dynamic.

Weber's classic work 'The Protestant Ethic and the Spirit of Capitalism' (Weber 1958) provokes a key question, one of simultaneous theoretical and empirical interest: is there any chance that computerisation will be associated with the formation of new social structures and new social actors? From the methodological viewpoint I was drawn to examine places where the seeds of the future, new forms of social action and new types of social actor might be sprouting. However, no empirical research was available concerning Brazil which permitted one to see 'the emerging'. I was thus drawn towards adolescents who, wherever they are, reflect the present and construct the future. What are Brazilian adolescents doing with computers? Are new forms of social action to be observed among them? How do these relate to other more conventional forms of action?

\section{ETHNOGRAPHIC RESEARCH}

Ethnographic field research was carried out over a three month period amongst Brazilian adolescents in three cities in the state of Sao Paulo. The research studied some 80 adolescents and 40 of these in detail. The major revelation was the existence of three distinct groups of computer users. Secretaries, engineers and authors. Each group uses the computer in a different way and it is this which is full of importance for the development of products and for the computer's capacity serve as a lever in processes of social, political and economic change.

Secretaries use computers to do what they are already doing but in a digital form. In schools, for example they use them to reorganise and make presentable what they normally work on. Far from using the computer as a lever to innovation, it serves as a new medium in which to produce.

Engineers take a series of ingredients and their perception of a basic problem and, within the frame of reference adopted by holders of utilitarian values, go about building a product capable of resolving the identified problem.

Authors seek to explore the capacities of computers and other modern technologies to develop new products and in so doing learning, human 
development or self development are involved in a creative process. Utilitarian values do not underlie the principal motivations for their actions.

\subsection{Secretaries}

Secretaries could be found amongst pupils in upper-middle class private (non-technical) schools and in a group of boys of lower class origin who work in large companies, these are known as 'office boys'. This latter group serves to illustrate the general principle about secretaries. Typically office boys do a variety of tasks in a company. At one moment they a dogsbody in the firm, distributing mail, running messages within and outside, going to the bank. At another, when the administrative secretary to whom they are subordinated is at lunch, at a meeting or has yet to arrive, they become the receptionists for their department, ushering visitors to staff members, answering the phone, doing urgent typing. The rest of the time they are assistants to the administrative secretary or trainees in some functions. It is as trainees, most often as self-appointed trainees, that their work becomes an investment in their own futures. It is as messengers that they acquire liberty from the constraints of daily workplace living, and pick up the codes of the rest of the office boy world outside of the firm. They use the computer for three types of activities: work, school work and playing games. When they use the computer, they frequently merely produce better quality versions of work letters, school assignments and play different games to what they would have had they not had access to computers.

A similar pattern of activity in relation to assignments and game playing is to be found among many students in middle class schools who have restricted access to computers in the school or at home.

\subsection{Engineers}

Engineers were located principally in studies carried out in three technical schools in the interior of the state of Sao Paulo. What do they do? Two boys have built a 'digital aquarium' which contains information on how to maintain an aquarium, the types of fish, water temperatures, types of food and other information. A boy and girl team, following their teacher's suggestion, executed a project for computerising a 'food bar'; in order to guarantee a market they have tried to produce a programme that is easy to use. The programme includes stock control, menu and accounts amongst other things. A group of four pupils spent four months working on a program for managing a parking lot. It includes lists of clients, suppliers, staff and maintenance. Another mixed-sex two-person group has, with the help of a doctor, written a spirometry program which measures lung capacity. To build this software the pupils had to study biology! A girl has written a programme for a book shop, and at home has produced another for her father's drink distribution business. Other recent class exercises have included computerising a car rental company and an airport. These are just 
some of the programs developed; as such they provide a first window through which to look out at this world.

Engineers frequently see the use of computers as only contributing to individual profit-making, often having chosen to get involved because, in one girl's words, "it's the profession of the future". The engineers have a very career-oriented discourse. In the main, they see a certain inevitability in the type of technological development that is occurring, and different to the authors, have no project of changing its course. Technology exists and is seen as a product of evolution of the human spirit without being linked to concrete social actors and their interests. However, some do express preoccupations about the rise of information society and its incapacity to transform Brazilian society. "Computers are another world, how are you going to talk about information society to those who don't have enough to eat?" Another student adds "What does a person who lives in a slum ('favela') need? She doesn't need a computer she needs a house to live in, money, a job. After resolving basic social questions then she's going to want a computer." A boy, however, has an apocalyptic view of the result: "society will self-destruct because it is totally egoistic, I include myself in this because I'm not perfect... I try to act in the best way possible."

\subsection{Authors}

As a group, the authors are interested in producing the new, and in this study their preoccupations were found to be largely aesthetic. Their use of computers is not motivated by utilitarian conceptions of what should be done to guarantee their own futures. Play and art attract, and the computer affords them the power they need to put ideas to work.

Two female technical college students are taking a course in multi-media and have decided to end the year with a class-book project. Photos of class members are scanned and then arranged so that they change automatically. The influence on their electronic 'book' comes from of the opening scenes of the 8.30 p.m. Globo soap opera 'Next Victim', where the images of personalities in a story of passion and murder occurring against the background of Sao Paulo city, compose and decompose. Their book is set to music and the image of one student dissolves with that of another taking its place. It constitutes a first step towards authoring and as such was found to be extremely rare amongst the technical school students included in the research.

Three further groups were found and all were made up of white (or Japanese-Brazilian) male and upper-middle class adolescents, I shall relate the activities of two of these. My research assistant and I tried to locate female-author groups but, with the exception of the two girls mentioned above, this was to no avail. Girls seem to prefer making videos and writing on paper for their schoolwork and, in their leisure hours, prefer to cultivate interpersonal relations rather than to "muck around" with machines. This 
impression about female activity was confirmed through interviews with teachers, boys and girls, as well as through observation.

One of the groups makes 'zines. "Music, cinema and literature" is what they define as their path. They see themselves as being caught up in a "globalising culture, where people absorb many tendencies... you like American cartoons, you like what's good, you can't be radical... you can't be with those who think that only things in English are good nor with those who think that Brazilian singers should only sing in Portuguese... barriers limit a lot. We have an idea of defending Brazilian things, there are good Brazilian things that are worth being seen out there." The 'zine, which may soon become a CD-Rom or a page on the Internet expresses this desire "to spread the word".

Another group is engaged in making a game. It has shades of 'Bladerunner: a decadent future'. It is a multi-media game which presents a history of the World until the year 2020 that starts, significantly, in the United States where the government is engaged in hiding what the post industrial society most prizes - information. The story includes contemporary and global themes: energy crises, the power of the State, the role of ethnicity and artificial life. Through hypertexts, the player is transported to any of a dozen cities and, in each, mysteries and action occur close to various monuments and also in the suburbs. The game is international in flavour, its cities splashed across four continents, it is an urban maze, a collage of the type post-modern urbanists love. Science fiction, mystery and adventure are mixed up into one story. In one of its night-time scenes, remembering Hitchcock's film 'Rear Window', a decaying apartment building can be seen with a computer in every window.

This group is embarking on what, for each and every one of its members, appears to be their biggest ever computer adventure. It is a low cost, backyard operation relying heavily on borrowed and parental resources and pirated software, it is filled with challenge, excitement and, for some, has high potential payoffs.

"They say that we don't have any more imagination, man has no idea of what he can do!" What attracts this adolescent to technology is "ease of use" and "simplicity". "I do simple things and everybody says 'My God!' I go on wanting to discover things." "We go after pirate programs", he eagerly volunteers. Another adds, "We go after fun, games, texts, even schoolwork."

Originally the group wanted to put the game into shareware and then to try for publication. Although all look towards publication the group divides as to what, exactly, 'publication' signifies: one member (who has already been hired by the computer industry and subsequently left his job) seeks recognition of his talent as a programmer; another (who is being hired on a part-time basis by a computer company operating in the educational area) sees publication as representing a pioneer effort in the Brazilian software industry, producing a game that is world class; a further member is sceptical as to whether publication, although desirable, will ever be possible (he cites 
the power of American industry, widespread pirating, the fact that the group is made up of amateurs, the lack of farsightedness of Brazilian investors and the lack of appropriate publications capable of evaluating and publicising the software) - 'Doom' and other games, he is reminded, were "made by people just like us."

\section{ENVIRONMENTS FOR GROWTH}

Secretaries tend to form in environments where there is a limited access to computers or the individuals do not have motivations to work with them. Engineers, on the other hand, have greater and occasionally unlimited access to computers, they have adequate technical support and their motivations, which play a large part in shaping their activities, are largely utilitarian. Authors have similar access to computer resources as engineers (although they frequently need more advanced resources), find strong technical support at school or in group or family circles and, as opposed to all other users, find that their positive personal motivations towards use are not channelled towards specific objectives set by parents or teachers but rather their own efforts are stimulated.

\section{THE FORMATION OF SOCIAL ACTORS AND LINKS TO SOCIAL CHANGE PROCESSES}

In looking towards chances for social change, the secretaries constitute a reference group only when we consider the barriers that limit their capacity to engage in practices capable of producing transformations. The research revealed that many office boys wished, for example, to engage in more ample uses of computers, becoming engineers or even authors. What limited their capacities for action were not motivation (of course some lacked appropriate motivation as did many middle class secondary school students) but restricted access to equipment. The case of Washington, a 15 years old with " 8 months and 3 days" service as an office boy, is illustrative of how office boys with access to appropriate equipment can engage in levering social change not only at a personal but at a family level, as he has made an entry into the low-end of the engineers group. MS-DOS, Word, DBase and Lotus were learnt at a private computer course. These qualifications, acquired from the age of 13, gave the youngster an opportunity to help the family budget, through running some of the financial affairs of his father's small construction company. Washington spends an hour and a half each week drawing up quotes for clients, quotes that would, in the past have been done by hand or typewriter. They have a more professional look than those of immediate competitors. He therefore mixes secretarial and engineering skills. He now recognises the need to develop the skills to draw up spread sheets and cost calculi.

Change can also be observed in other situations where the computer skills of adolescents were linked to the needs of parents in their business ventures. 
This was more easily observable in middle class settings. Carlos' father is an engineer employed by the public service, however the family has inherited a cattle farm. Carlos uses DBase and he has put all of the animals, their weights and other variables on the computer and this is his way of helping his family earn money. Sixteen year old Julia says that she doesn't know how to work with the computer. In spite of this statement her mother, who owns a small publishing company, recruited her for a semester to help set up a BBS. Fernando saved up pocket money with his brother to buy a computer and his grandparents topped this up. He soon found a way to help his mother, part owner and administrator of a chain of furniture stores, to do her work. He does her mailings, prints out price tables and sets up flyers.

This multitude of activities suggests a fruitful area for future investigation and, in particular, in cross cultural settings. These observations made in Brazil contrast with occasional reports received from wealthy countries where importance is not attributed by youth to the use of computers as a means for economic progress of the family unit. While it is still too early to develop hypotheses about the general significance of the observed phenomenon some preliminary remarks can be made. A more general access among members of families which are in a position to use computerisation to increase income can contribute to raising relative income levels. This may contribute to increased economic efficiency and simultaneously produce inequalities between those families with access to such resources and their counterparts without such access. To the extent that differential access is grounded in social structural variables (e.g. builders of working class origin such as Washington's father don't have such resources available to them as commonly as their counterparts of middle class origin) developing inequalities will follow predictable patterns. To the extent that the systemic nature of such patterns between social classes or groups can be broken, new patterns of social mobility will be expected to emerge.

However, engineers, as was said earlier, do not produce the new. Authors do this. The importance of Washington's case is that it illustrates the necessity for those who reflect on the role of computers in society to research and theorise around the structural conditions which will permit more Washingtons to emerge (in his case his father's acquisition of a cheap second hand computer was fundamental) and thereby permit youthful creativity and energy to flow in directions capable of leading to the production of ideas as to how computerisation might help in the resolution of the needs of the lower classes, both individually and collectively. Ideas can, of course, subsequently be transformed into action. The ethnographic study mainly isolated economic activity in this context, however nothing impedes engineers, acting in terms of less material values, from turning their concern to aspects of computerisation capable of transforming peoples' currently structured relationships to political or social systems! Empirical research is necessary to construct images as to the extent to which this is occurring and its effects. 
However, for innovation to occur in a way that shakes up social structures and ushers in a new era it is of fundamental importance, as in the period of European industrialisation, that new value systems, new principles of organisation and new aesthetics be produced. It thus becomes a necessity to counteract the tendencies towards inequality that many link to the rise of computerisation, to stimulate the activities of authors. In this way creativity will contribute to the construction of new social fields and, through this, to the reconstruction of the parameters of action.

\section{TOWARDS THE FUTURE}

The ethnographic section of this paper has made a very limited attempt to examine the relationship between three distinct groups of Brazilian adolescents and computers.

In attempting to look towards the future, various issues emerge. Three broad categories of issue can be defined: information, interests and culture.

What kinds of information will people want and how will they want to process them? This paper allows a series of answers to these questions to be traced for each of the three categories researched. For secretaries, better interfaces will assure an easier management of interrelationships between information from different sources, access to library resources and data, image processing and manipulation, and schooling, to name just a few. For engineers, information about what other programmers are doing, the development of networks of co-operation with appropriately skilled people, knowledge about client difficulties, and adequate training in programming techniques appropriate to the times are necessary. Authors require various resources for managing the information they handle: speed, memory, and better interfaces. They also require investments in software, a change in the quality of telephone services amongst other things. A part of the response to demands for information depends on factors at the other two levels.

Will a series of interests be built up that is sufficiently strong to permit the development of infrastructure and State investment in certain key sectors? The answers to this question are partly dependent on the speed at which certain political reforms are made and subsequently the underdeveloped country's capacity to attract investment capital. Should such interests build up and consolidate they may be able to alter current patterns of investment in various sectors of the Brazilian economy including the educational one where the use of computing is currently largely restricted to the elite private school system. The capacity of implementation of such technologies in this and other sectors may, subsequently, meet with reactions from certain social categories who, in defence of their interests, fear technological change. The ethnographic research identified a widespread fear that such change will generate unemployment; the question becomes, to what extent such an issue might affect configurations of interests? 
At the cultural level, a key question facing those computer and technology manufacturers that dominate today's markets is, will they display the creativity to build projects capable of replying to the needs of, and creating demands among, those consumers who today choose only limited forms of integration into the world of computing? From a business viewpoint the Brazilian market certainly still has a lot of room for expansion. The easy route would be to continue selling products developed in the wealthier countries to the more 'knowledge intensive' parts of the business sector and to upper-middle class homes and schools. Values and products would be easily matched up through such a process.

The question then becomes, and what about the rest of the population: the girls, the lower middle classes (and below), rural populations, those who work only at unsophisticated secretarial levels, etc.? Creative manufacturers, operating in terms of ideas that do not dominate today's market, may find their place building new products that meet up with consumer expectations and values.

The future depends to a large extent on creativity, however the extent to which creative projects are taken up and how they feed into new demands is often difficult to predict.

"We want to transform the computer into a medium, just like theatre and cinema are separate and show people doing the same types of thing, we want to make an autonomous art form". Should even a part of this adolescent author's project start to realise itself - linking up with new and compatible orientations in the classroom, complementing video, drawing and the written word as a form of legitimated expression - we would be talking not about a change in reality but about a change (that appears to be already under way) in how reality is represented, and in this case we are talking, at very least, about a change in the status of the written word. Here, indeed, is an area of fundamental importance for a developing country and its capacities to bypass a phase of classic literacy to move towards another, thus building new capacities to see the world and to imagine it free from many of the limitations and demands imposed by the horizons set by the industrial order.

\section{NOTES}

1 This is to be found more frequently in Europe than in the United States (Despin and

2 Bartholy 1987, Hill 1990). For a more bar earlier view see Sieghart (1985). 


\section{REFERENCES}

Bell, D. (1973) O Advento da Sociedade Post-industrial. Cultrix, Sao Paulo. p. 532.

Cardoso, F. H. e Faletto, E. (1973) Dependencia e Desenvolvimento na America Latina. Rio de Janeiro, Zahar.

Castells, M. (1996) The Rise of Network Society. Butterworths, Cambridge, MA.

Despin J.-P. and Bartholy, M.-C. (1987). Arsenic et jeunes cervelles. Paris, 10-18.

Dubet, F. (1987) La galere: jeunes en survie. Fayard, Paris. p. 401.

Dwyer, T. (1989) Um salto no escuro. Revista de Administrato de Empresas 29(4) 29-44.

Elie, M. (1996) Internet et developement. Futuribles. Novembre, 43-64.

German, C. (1997) Caminhos e descaminhos para a sociedade de informatio. Sao Paulo, Fundatio Konrad-Adenauer-Stiflung. Paper 31, pp. 31-51.

Hafner, K. and Markoff, J. (1991) Cyberpunk. Simon and Schuster, New York.

Hill, S. (1990) The tragedy of technology. Pluto Press, London.

Levy, S. (1984) Hackers: Heroes of the computer revolution. Dell, New York.

Sieghart, P. (ed.) (1985) Micro-chips with everything. Comedia Publishing, London. pp. 3258.

Toffler, A. (1980) The third wave. William Morrow and Co., New York. pp. $319 \mathrm{ff}$.

Touraine, A. (1969) La societe post-industrielle. Danoel, Paris.

Weber, M. (1958) The Protestant Ethic and the Spirit of Capitalism. Scribners, New York. 